\title{
LA PINTURA EN LA HISTORIA MEXICANA RECIENTE *
}

\author{
Por Jorge Alberto Manrique
}

\section{La pintura de la "escuela mexicana" y la Revolución}

Para los efectos de este artículo conviene tomar como punto de partida, para analizarla y después matizarla, una afirmación muy a menudo hecha acerca de la pintura de la "escuela mexicana" o "pintura muralista mexicana", es a saber: la afirmación que sostiene que esa pintura es hija de la Revolución Mexicana o producto directo de ella.

Personalmente creo que esa afirmación no es falsa, pero tampoco totalmente verdadera; no, por lo menos, en el sentido estricto en que a menudo se toma. No es, creo yo, que la Revolución por sí misma, haya producido un movimiento pictórico con características precisas y definidas. Las revoluciones, movimientos políticos, sociales y económicos, no producen formas artísticas, ni siquiera teorias artísticas: únicos elementos - que esos sí- pueden hacernos reconocer o distinguir un movimiento artístico. No produjeron por sí mismas, directamente, ni formas ni teorías artísticas ni la Revolución Francesa ni la Revolución Soviética (para poner dos ejemplos ilustres), aunque sí, ciertamente, propiciaron el florecimiento de algunas tendencias que ya se anunciaban antes del estallido revolucionario: el clasicismo civilista y el populismo romántico para el caso de la Revolución Francesa, o el suprematismo para el caso de la Revolución Bolchevique. En las dos situaciones citadas se trata de teorías y formas artísticas que venían ensayándose años atrás, y que con la circunstancia revolucionaria pudieron hacerse más explícitas.

Estos dos ejemplos, creo yo, nos abren el camino para entender y matizar la afirmación de que "la pintura de la 'escuela mexicana' es producto de la Revolución". Si la Revolución no la produjo directa-

- Las ideas centrales de este artículo fueron presentadas en forma de conferencias, en el Museo de Bellas Artes de La Habana, el 7 y 9 de enero de 1975. Las pláticas tenían el doble objeto de presentar algunas ideas propias sobre la pintura mexicana, y de comentar en alguna forma la exposición de pintura mexicana que en ese momento se presentaba en aquel museo, llevada por una embajada cultural de nuestro país. El presente texto, sin embargo, no es el leído en aquellas ocasiones, y ha sido descargado de buena parte de los datos informativos destinados al público asistente a la exposición. 
mente, sí es posible decir que la experiencia revolucionaria (aun en el caso tan complejo y difícil de deslindar que presenta la Revolución Mexicana) propicia -y propició sin duda entonces- un clima de rompimiento, de apertura, de negación de un pasado inmediato; de entusiasmo renovador; y ese clima si hizo posible que se resolviera en un hecho plástico concreto un conjunto de ideales en el terreno de la cultura y del arte mexicanos, que eran ya, algunos, viejos de más de cincuenta años. A su vez, la resolución de esos viejos ideales se entretejió con las "ventajas" que ofrecía, precisamente para resolverlos, el arte de la vanguardia europea de los primeros veinte años de este siglo.

\section{Los ideales}

Veamos, pues, un poco, cuáles eran esos ideales, de antemano formulados, que pudieron abrirse paso a su resolución aprovechando -diremos- la coyuntura del clima revolucionario. Para que éstos nos resulten claros y con médula (no como simples volátiles entelequias) será necesario hacer referencia, así sea apenas ligera referencia, a algunos hechos más generales de la historia cultural de México.

Pienso que una característica muy definida de la historia y la culturra de México es la apremiante necesidad que sentimos, continuamente, por definirnos y redefinirnos, por dar cuenta de quiénes somos, por decir a los otros quiénes somos (en esfuerzo consciente o subconsciente por afirmar la idea que de nosotros mismos nos hemos hecho). Esta característica creo que puede hacerse extensiva a los pueblos americanos, pero especialmente a los pueblos de la América Latina. Pueblos marginados respecto a Europa, los nuestros tienen naturalmente una participación ambigua, una participación profunda y quizá indeclinablemente ambigua de los valores de lo que se suele llamar la cultura occidental. A la vez o alternativamente de rechazo y de aceptación. Nosotros nunca llegamos a saber (digo: nunca llega a haber un consenso claro en este sentido), puestos frente al dilema, si somos "occidentales" o si no lo somos; cuando decidimos por la afirmativa, mil instancias se levantan por la contraria, y viceversa.

Está claro, para mí, que tal situación se genera de que sí somos "europeos" de alguna manera, pero que también de alguna manera no lo somos. $\mathrm{Y}$ es eso lo que nos lleva a esta necesidad de definición que 
nos asalta constantemente, y que alternativamente nos lleva a definirnos a veces como occidentales y a veces como no occidentales. Entiendo yo que es ésa la espina dorsal de la historia de la cultura mexicana, más o menos explícitamente, desde el día siguiente a la Conquista, hasta ahora. $Y$ es esto lo propio de México como del resto de nuestros países. Ésa, que es su debilidad, es su fuerza. Marginados, explotados, los americanos hemos cumplido a través de nuestra historia esa gran aventura que nos identifica: la de definimos frente a "lo otro", "lo orro" que es, fundamentalmente, Europa, y ahora los Estados Unidos. Antes de seguir se me hace preciso puntualizar dos aspectos:

a) Aunque en principio la posibilidad de definirse por los parecidos o por las diferencias se da en una misma persona, y aunque de hecho se dé en diferentes personas simultáneamente, es más común ver las dos. posibilidades de interpretación en momentos alternantes, que se suceden uno a otro; lo que depende en gran parte de otros factores históricos, que están en estrecha relación de dependencia mutua con los hechos culturales y artisticos.

b) Como historiador no veo a ninguna de las dos interpretaciones como positiva y a la otra como negativa, sino a ambas como necesarias en sus respectivos momentos históricos. Menos todavía creo que pueda calificarse fácilmente a una como reaccionaria y a otra como revolucionaria -lo que es bastante frecuente hacer. Una y otra se pueden calificar de revolucionarias en su ascenso y de reaccionarias en su declive. Para poner un ejemplo: a los fines del siglo xvin lo revolucionario y lo valiente era hacer el internacional arte neoclásico, mientras que lo reaccionario era hacer el nacionalista arte barroco.

Este largo rodeo ha sido para permitirnos apreciar el sentido profundo e histórico que una actitud nacionalista tiene cuando se manifiesta en la cultura mexicana. El primer ideal que la pintura de Rivera, de Orozco y de los demás alcanzó fue el de ser, el de lograr ser profundamente nacionalista, incontrovertiblemente nacionalista. Se anunció a sí misma como una voz mexicana y latinoamericana. Es decir, la fintura mexicana que se practica a partir de 1921, ya en el mural, ya en el caballete, toma el partido de definir lo mexicano y lo americano como diferente ante los valores de la cultura europea. Esa pintura, estrictamente lo que se conoce como "escuela mexicana", daba su res- 
puesta sobre el ser mexicano, y esa respuesta consistía en señalar lo propio, lo individual, lo específicamente mexicano. A nadie escapará, pienso, que esa postura nacionalista -que por otra parte coincide con el clima general de la cultura nuestra en esos años- representó un paso más en la cadena de respuestas alternas que sobre nuestro ser los mexicanos hemos ido dando a través de nuestra historia; y a nadie escapará tampoco que siendo eso, la "escuela mexicana" era también la realización de un viejo ideal formulado desde el siglo xIx, ideal que México compartió entonces con las otras naciones del continente, y que se manifiesta como el desiderátum de crear un arte nacional expresado en un lenguaje universal que puede calificarse de romántico, y esto sólo le dio a la "escuela mexicana" un brillo particular desde sus principios: porque había sido capaz de lograr lo que en la teoría estaba propuesto desde hacía mucho, pero que en la práctica no se había alcanzaclo, en ningún país americano, sino débil y parcamente.

Además de ser fundamentalmente nacionalista, la pintura de "escuela mexicana", que nos definía a nosotros mismos como diferentes y que se constituia ella misma en prueba de que un pueblo americano cra capaz de tener una voz propia, nuestra pintura lo hacia en un lenguaje que, siendo propio, podía ser escuchado y entendido fuera del propio ámbito nacional: es decir, señalaba lo propio con un lenguaje universal. Y en esto también se cumplía un ideal formulado en México desde los años de la República Restaurada, en ese ambiente de euforia liberal y nacionalista de la triunfante República de Benito Juárez cuando pudo restablecer la legalidad y arrojar a los invasores extranjeros: el ideal de un arte nacional con dimensión universal, que formularan liberales como Ignacio Altamirano, Manuel Olaguíbel, López López y junto a ellos, José Martí, que para esos años residía en México y escribía crítica de arte, posiblemente la mejor crítica de arte que entonces se hacía en México.

Me importa señalar una aparente contradicción: si la pintura mexicana, siendo nacionalista, pudo poseer un lenguaje universal, esto se debió a que formalmente aprovechó las ventajas que le proporcionaban los ensayos formales de la primera vanguardia europea: el fauvismo, el cubismo, el expresionismo, e incluso la posibilidad de incorporar las formas de arte prehispánico y de arte popular. Es decir, los pintores mexicanos no dieron la espalda a lo que en materia de arte estaba pasando en Europa; algunos de ellos habían participado en esos movi- 
mientos vanguardistas, como Diego Rivera, y otros estaban al tanto de esos movimientos, y su traza puede encontrarse en sus obras. Véase, pues, cómo para ser universal, la pintura tuvo que ser necesariamente, moderna.

$\mathrm{Y}$ aquí también parece oportuno y conveniente hacer referencia a lo que sucedía en otros países americanos. En muchos de ellos, precisamente en los años veinte, aparecen diversos movimientos artísticos cuyo fin es poner al día la actividad artística de cada uno, sacarla de la situación colonial de atraso y colocarla a la altura de los tiempos. Casi todos esos movimientos muestran, en forma más o menos explícita, también una preocupación por encontrar el timbre americano y personal de su arte. El movimiento mexicano, en última instancia, se inscribe dentro de esa inquietud similar que recorre por entonces a América. La única diferencia es que en el caso mexicano los fines se deslindan con mucho mayor claridad -quizá porque en esencia estaba la situación más claramente planteada-: y creo que el éxito de la pintura mexicana, sin descontar el personal talento de sus creadores, se debe en buena parte a esa circunstancia, favorecida por el ambiente de eurofia revolucionaria.

Todavia señalaré otro rasgo principal de la "escuela mexicana": su. decidida preferencia por la obra monumental, por el mural.

También en este caso podemos advertir dos vertientes. Por un lado, al ser monumental, la pintura mexicana intenta rescatar el antecedente del arte prehispánico y colonial, ambos creadores de magnificas obras monumentales, pero que no tienen prácticamente secuela durante el siglo xix. Pero también el hecho de ser monumental implicaba para los pintores un especial compromiso hacia el público; o más bien dicho, porque los artistas sentían ese compromiso con el público es que sintieron clara la necesidad de hacer pintura mural. En este sentido la pintura mexicana tomaba un problema que se habia hecho actual en diferentes casos de la vanguardia europea, es a saber, el problema de restablecer la relación arte-público. Pero daba su propia y personal respuesta.

La escena en 1921-1922 y su secuela

Para poder distinguir cómo las circunstancias y los diferentes elementos dieron la posibilidad de que se estructurara un movimiento 
artístico como el de la "escuela mexicana", y para entender las secuelas de ese movimiento, quizá sea conveniente fijar un momento nuestra atención en los primeros años de la década de los veinte, en el preciso momento en que aparece la pintura mexicana con las características que he señalado.

Después de diez años de lucha armada, trágica y dolorosa como toda lucha armada, la Revolución Mexicana iniciada en 1910 se había ido definiendo, habia podido aclarar sus fines, especialmente se había ya mostrado como un movimiento que procuraba restructurar socialmente al pais. El primer gobierno que goza de paz y tranquilidad relativas es el de Alvaro Obregón, y se da a la tarea, de rehacer al país con las bases de la Constitución de 1917 y las ideas que habían surgido durante diez años de lucha, en lo agrario, en lo que respecta a la situación de los obreros, en lo económico y en lo educativo. Obregón nombra a José Vasconcelos rector de la Universidad, primero, y luego secretario de Educación Pública, y Vasconcelos emprende, en esa Secretaría, uno de los esfuerzos más completos y más bellos que puedan darse por la educación popular y por la definición de la cultura nacional. Si la época de Porfirio Díaz, anterior a la Revolución, había tratado en muchos aspectos de definir a México por sus similitudes con Europa, y se había empeñado en mostrar que las diferencias eran sólo aparentes, que en última instancia México podía ser un pedazo de Europa de este lado del Atlántico, la época posterior a la lucha armada, en ese vaivén constante que creo característico de nuestra cultura, intentó definir la cultura nacional por lo que tiene de propio, de individual. Eso fue lo que de alguna manera Vasconcelos procuró como secretario de Educación Pública.

En ese inomento, de acuerdo con el tono de la época y con la orientación de la Secretaría de Educación, Vasconcelos invita a varios pintores, jóvenes entonces, a decorar con murales algunos edificios públicos.

No es de extrañar que lo hiciera: lo que sí sorprende es que desde un principio la pintura surgida de esa iniciativa fuera una gran pintura y que desde el principio también hiciera aportes novedosos e importantes en el ámbito del arte. En 1922 los artistas, todos ellos de izquierda con diferentes matices, se organizan en un Sindicato de Artistas Revolucionarios, que lanza un "Manifiesto". El texto de ese "Manifiesto". redactado cuando ya varios de los artistas habian realizado sus primeras 
obras será, sin embargo, el programa de lo que pretendía ser la pintura mural.

El "Manifiesto del Sindicato", dirigido a "los obreros, los campesinos, a las razas nativas humilladas a través de los siglos, a los soldados convertidos en verdugos de sus jefes, a los trabajadores y campesinos azotados por los ricos", sólo en última instancia se refería a "los intelectuales que no adulan a la burguesía”. En él se repudiaba el arte burgués, se pedía un arte público (por lo tanto monumental), que propiciara los cambios revolucionarios y que tuviera por fuente de inspiración el arte popular.

Lo importante no fue que los artistas se atuvieran al texto del " $\mathrm{Ma}$ nifiesto" (algunos lo criticarían después rudamente), sino que éste proporcionó una base teórica como punto de partida. Si el movimiento pictórico mexicano de entonces es reconocible como una unidad, y si sus fines fueron más claros y definidos que los de otros movimientos que por esos años o un poco después tuvieron Iugar en América, eso se debe, en buena parte, a la existencia del "Manifiesto".

Al fin y al cabo, cada uno de los pintores entendió, sin embargo, el texto del "Manifiesto" a su propia manera, y siguió desarrollando su pintura con entera libertad. Todos, sin embargo, coinciden en ciertos puntos, como en la conveniencia de un arte monumental, y en la necesidad que todos sintieron para dar a su pintura un contenido especifico. Personalmente no creo que una obra de arte deba tener por fuerza un contenido definido, sí creo, sin embargo, que para entender una pintura que se propone explícitamente un contenido, es necesario entender a éste: no por parecernos más o menos válido aumenta o quita valor a la obra de arte, pero sí es un elemento que necesariamente debemos tener en cuenta si queremos entrar al fondo de la obra que Io propone. Tal es el caso en la pintura muralista mexicana, a la que Justino Fernández calificó como "pintura filosófica", porque por medio de las formas artísticas se propuso hacer luz sobre problemas que se refieren al ser del mexicano y al ser del hombre. Todo lo cual, repito, no impidió que cada pintor desarrollara su propia ideología y sus propias formas.

Veamos someramente algunos ejemplos:

Diego Rivera es el pintor que con más convicción cantó la Revolución triunfante, la que a él le tocó vivir y la Revolución definitiva que esperaba para el futuro; fue también el más claramente nacionalista, 
quien más literalmente tomó la idea de inspirarse en las formas del arte popular y del arte prehispánico; también fue gran optimista en el progreso técnico. Su estilo puede calificarse de "clásico", en tanto que prevalece en él un espíritu racional, que se manifiesta en su preferencia por la línea que define claramente las figuras, por la ordenación pausada de sus compoiciones. Es también el pintor que más se preocupó por el sentido didáctico de sus murales y por hacerlos de lectura fácil para un público amplio: en su interpretación de la historia y de la realidad mexicana aparecen siempre los buenos y los malos claramente representados e identificables como tales.

José Clemente Orozco, en cambio, es el espectador azorado del drama humano que fue la Revolución; se pregunta constantemente cuál es el ser de México, sin tener él mismo una respuesta cierta; contrariamente a Rivera, se muestra perplejo ante el pasado prehispánico, que le resulta siempre impenetrable, y desconfía terriblemente del progreso material, al que ve como opresor y no liberador de la humanidad. Es Orozco también el crítico acerbo y feroz de la realidad que lo rodea. Su estilo podria, calificarse de "barroco", en tanto que construye sus obras a base de pinceladas fuertes, que estructuran los conjuntos de formas indefinidas, en composiciones dinámicas a base de ejes transversales.

David Alfaro Siqueiros (dejando a un lado su papel preminente como luchador político), es el artista que ve el drama de la humanidad, pero no encuentra en ello motivo de queja, sino de lucha. El llanto del campesino, del obrero o del negro discriminado, o el problema de la definición nacional son para él la base de una lucha ciertamente más definida que en los otros. Lo rotundo de sus formas, la fuerza de su trazo son el vehículo para manifestar la certidumbre de sus convicciones.

\section{La escuela mexicana a distancia}

Como he dicho, la pintura de "escuela mexicana" apareció desde un primer momento como una gran pintura, y desde el principio tuvo un gran éxito. También he señalado que en los inicios de la escuela como tal estuvo el que el propio gobierno mexicano, por vía del secretario Vasconcelos, invitara a los pintores a decorar los edificios públicos. 
Estos dos hechos hicieron que fácilmente la escuela se convirtiera en arte oficial. Para el gobierno era una fuente de prestigio y un instrumento de política nacionalista; para los pintores la asistencia del gobierno era necesaria, pues casi sólo él podía proporcionar muros para el arte monumental. De esta manera, convertida en arte oficial, la pintura mexicana se vio en cierta medida comprometida con los diferentes gobiernos surgidos de la Revolución, que no todos tuvieron ciertamente la misma orientación. Es verdad que los pintores más importantes supieron mantener siempre la independencia de su arte y de sus actitudes frente al mundo oficial, pero no sucedió lo mismo con artistas menos. seguros de su propio valor y de sus posibilidades de realizar un arte personal.

Más grave que eso, el gran éxito que tuvo la escuela mexicana, tanto en el interior del país como en los Estados Unidos o en otros países de América que recibieron la influencia importante de los pintores mexicanos, se convertiría a la larga en un elemento negativo. En efecto, los pintores menos dotados y los de las generaciones que sucedieron a la de los llamados "tres grandes" se dieron con demasiada facilidad a aceptar las maneras que ya se hablan probado como exitosas: abandonaron así la búsqueda formal verdadera que está en la base de toda creación artística válida, y crearon una verdadera "academia" de la escuela mexicana, secándola así de su fuerza y sus virtudes.

\section{Nacionalismo y demagogia}

El México de la Revolución triunfante había propiciado, por razón natural, como hemos visto, una actitud fuertemente nacionalista. Pero ese nacionalismo plenamente justificado - pienso yo- tanto por razones históricas concretas como por el problema de definición del ser nacional que he indicado, al pasar de los años se fue convirtiendo en retórico y demagógico, y fue perdiendo verdadero contenido. De alguna manera la pintura de los artistas menores participó de tal retórica y tal demagogia, como participó también buena parte de la cultura mexicana hacia la década de los años cuarenta, justo cuando la producción de los artistas mayores empezaba a declinar. El nacionalismo a ultranza, en tanto demagógico, creó un ambiente cerrado, de aislamiento, impermeable y repelente a cualquier novedad que viniera del exterior. Un ambiente: 
nada sano, que en sus extremos resultó para, algunos verdaderamente intolerable.

Así las cosas, para los años cincuenta muchos mexicanos $-\mathrm{y}$ muchos pintores jóvenes mexicanos- se sentían íntimamente, apremiantemente necesitados de abrir ventanas hacia otras partes del mundo, de participar - para el caso- en lo que en términos de arte sucedía en otras partes del mundo. En la polémica que entonces se suscitó en México, los nuevos pintores que querían nutrirse de corrientes venidas de otras partes fueron atacados por extranjerizantes, "malinchistas" (el término mexicano más peyorativo para los traidores), y desde luego reaccionarios.

Si contemplamos el fenómeno a la luz de lo que he dicho antes, es a saber, a la luz de esa característica de la cultura nuestra que alternativamente se define por sus diferencias o por sus parecidos con la cultura europea, entenderemos que independientemente de los excesos en que sin duda cayó el nacionalismo de los años cuarenta, lo que sucedía era que el péndulo regresaba, y los mexicanos, así como en el pasado inmediato se habian sentido fundamentalmente diferentes, ahora se sentían con el derecho de ser hombres como cualesquiera otros, y de hacer lo que otros hombres hacian en otras partes. Como había sucedido en episodios anteriores de la cultura nacional -aunque cada vez con determinadas características específicas- los pintores mexicanos de los años cincuenta recesitaban abrirse al mundo. Contra lo que decían los ataques surgidos al calor de la polémica, era su actitud la valiente frente a la poltroneria de quienes querían seguir repitiendo el fácil juego ya visto y conocido; y contra lo que sostenian esos ataques, su actitud era revolucionaria en 10 artístico independientemente de la filiación política de cada uno: y vale la pena decir de paso, sin embargo, que varios de ellos eran políticamente mucho más radicales que sus opositores de "escuela mexicana", como entonces y posteriormente tuvieron ocasión de demostrar.

\section{Los maestros y las tendencias}

La charnela o bisagra que divide los dos momentos recientes de la pintura mexicana, o sea lo que se ha conocido como la "escuela mexicana", nacionalista, por una parte y la "nueva pintura mexicana", mucho más internacional, por otra parte, la bisagra, digo, se sitúa en la década de los años cincuenta. Pero sfntomas de ese cambio se pueden advertir 
mucho antes; antes de esos años algunos pintores no aceptaban la interpretación común sobre la cultura mexicana y buscaron un camino propio, ajeno a la escuela.

Los dos casos más notables en este sentido son el de Rufino Tamayo y el de Carlos Mérida. Tamayo, que terminaría de formarse fuera de México, repudió desde temprano la "escuela" por encontrarla retórica; él buscaba una pintura no superficialmente, sino profundamente mexicana (según decía), donde no fuera el contenido, sino la forma lo que diera razón de México. No procuró plantearse, como Rivera, Orozco - Siqueiros, problemas filosóficos, sino que entendió que el cuadro mismo, sin ninguna intención sobrepuesta, por la propia resolución de sus problemas formales daría una explicación del ser y de la circunstancia de su autor. Mucho más expuesto a las corrientes internacionales del arte, de las que aprovechó abundantemente, es especialmente famoso por su color indudablemente mexicano. Carlos Mérida, guatemalteco de nacimiento pero mexicano de adopción, también eludió toda retórica: un análisis más cuidadoso de las formas populares lo llevó primero a expresiones cercanas al surrealismo, luego a un geometrismo figurativo realizado con extraordinaria calidad. Tamayo y Mérida fueron los grandes ejemplos a seguir, puesto que para los jóvenes de los años cincuenta representaban la rebeldía frente a la "escuela mexicana", que ellos sentían anquilosada e incapaz de producir arte vivo. Todavía es necesario citar a tres pintores más, algo mayores que los de la "generación rebelde", que para los años cincuenta tenían ya una obra importante y alejada de la ruta inviolable que señalaban los corifeos de la "escuela": hablo de Juan Soriano, que había desarrollado ya un lirismo onírico muy libremente expresado a través de un trazo suelto, nervioso, de arabescos conlinuos; de Pedro Coronel, que pronto manifestó con sus formas fuertes y su colorido disonante el deseo de apoyarse en la "escuela mexicana". pero ir más allá que ella, y de apoyarse muy explícitamente en las formas de arte popular y de arte prehispánico, pero aprovechando al mismo tiempo las enseñanzas de la vanguardia europea; hablo en fin, de la obra callada de Günther Gerszo, que ha pasado de un surrealismo informal a un límpido geometrismo no por eso ajeno a una fuerte caja sentimental.

Los pintores jóvenes de los años cincuenta, que cambiaron el ambiente y clima del arte en México, se agruparon en contra de la "escuela mexicana", como expresión artística oficial; pero entre sí no constituyeron 
grupos que reflejaran tendencias artísticas identificables. Cada quien realizó su pintura en forma más bien aislada. Eso ha hecho que en la nueva pintura mexicana sea difícil distinguir, como en otros países, tendencias diferenciadas. Podemos, sin embargo, hacer un esfuerzo para referimos a ellos, agrupándolos en:

a) Expresionistas, como José Luis Cuevas, el fino y violento dibujante que expresa el interior de las cosas; como Felguérez en un momento de su carrera, como Francisco Corzas; como Alberto Gironella, que glosa obras maestras del arte del pasado a la luz del siglo veinte, con una iconoclasia irredenta, que lo acerca a veces a expresiones de tipo pop-art.

b) Geométricos, como Vicente Rojo, que siendo geométrico no se desprende de un intimo lirismo; como Manuel Felguérez en su época reciente, Kazuya Sakai o Helen Escobedo.

c) Abstractos liricos, como Lilia Carrillo, extraordinariamente fina y sensible o Fernando Garcia Ponce.

d) Surrealistas, que contaban con un viejo antecedente mexicano de arte fantástico y con la obra extraordinaria de Frida Kahlo, a lo que se sumó la presencia en México de las finas pintoras Leonora Carrington y Remedios Varo; como surrealista habría que considerar a Pedro Friedeberg, por más que su personal expresión resulte atípica y en buena manera se ligue a experiencias del op-art.

e) Neofigurativos líricos, como Francisco Toledo, que con extraordinaria fantasía y magnffica calidad pictórica recrea y recupera una visión mítica del universo; como Bryan Nissen, Roger von Gunten o Fnrique Guzmán.

\section{Colofón}

El resultado de los procesos artísticos suele ser a menudo ambiguo y contradictorio. He dicho que cuando, a raíz de la Revolución, se inició la aventura de la "escuela mexicana" bajo el signo de un incisivo nacionalismo, su éxito y la posibilidad de realizar su programa estuvo ligado al conocimiento crítico que esos artistas tenfan de la vanguardia europea. Ahora, cuando la pintura activa de México, la "nueva pintura mexicana" no se preocupa por ser especificamente nacionalista, y sí de 
participar en las experiencias que se realizan en otras partes del mundo, de hecho, por la situación especifica en que se ha dado sigue siendo de alguna manera nacional y creo que identificable entre los que producen otros países en materia de arte. Como esta nueva pintura se construyó como respuesta a la escuela mexicana, por diferentes que sean sus tendencias revela a menudo un aire de familia. No deja de ser sorprendente, por ejemplo, que ninguna de las grandes corrientes del arte internacional, por más que hayan influido e influyan en nuestro ambiente, sea practicada en forma literal por ningún artista mexicano importante.

Pero, una vez más, ese resultado aparentemente contradictorio no debe sorprendernos y se explica quizá por razones más profundas. Si pensamos en la premisa que he puesto al inicio de esta charla (el definirnos constantemente, ya por nuestras diferencias, ya por nuestras similitudes), podemos entender que si en el actual momento el arte y la cultura mexicana están menos preocupados por expresarse en formas nacionalistas, subsiste necesariamente un elemento nacionalista, menos fácilmente identificable, pero real, que afecta todo lo que la cultura mexicana produce.

De esta manera, como en otros momentos de nuestra historia, donde quiera que el acento se haya ido colocando, de acuerdo con las precisas circunstancias históricas de cada momento, el arte mexicano ha ido siendo, va siendo hoy en día, la expresión del doble ser de México: que tiene un rostro hacia Europa y lo europeo (léase también Estados Unidos) y otro rostro hacia su pasado -y su presente- no europeo. 